\title{
Low-Temperature Hypergolic Ignition of 1-Octene With Low Ignition Delay Time
}

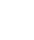

4

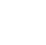

(1)

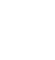

$$
\text { Haoqiang Sheng, Xiaobin Huang }{ }^{*} \text {, Zhijia Chen, Zhengchuang Zhao, Hong Liu }
$$

$$
\text { Shanghai Jiao Tong University }
$$

School of Aeronautics and Astronautics, Shanghai, 200240, China

*Corresponding Author : E-mail: xbhuang@sjtu.edu.cn

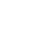

Supporting information

\section{Ignition delay time of 1-octene/BDMS at various volume ratios}

Ignition delay time is measured in the case of ignition. In general, the ignition delay time of fuel decreases with the increase in temperature. However, if at a certain temperature the volume ratio of 1-octene/BDMS is lower than a specific ratio, the fuel will not be hypergolic ignition. The volume ratio of 1-octene and BDMS was set at 9:0.6, 9:0.9, and 9:1.2 to ensure the hypergolic ignition of 1-octene at 50, 25, and -15 ${ }^{\circ} \mathrm{C}$, respectively. Therefore, the volume ratio of 9:0.6, 9:0.9 is not feasible for ignition at $-15{ }^{\circ} \mathrm{C}$, and, similarly, the volume ratio of 9:0.6 cannot cause hypergolic ignition at $25{ }^{\circ} \mathrm{C}$. The data for 9:1.8 $\left(25{ }^{\circ} \mathrm{C}\right), 9: 1.5\left(50{ }^{\circ} \mathrm{C}\right), 9: 1.8\left(50{ }^{\circ} \mathrm{C}\right)$ are shown in Fig. S1. When the temperature rises to $50{ }^{\circ} \mathrm{C}$ and the content of BDMS is higher than 1.2, the volume ratio has little influence on the ignition delay time of this fuel. 


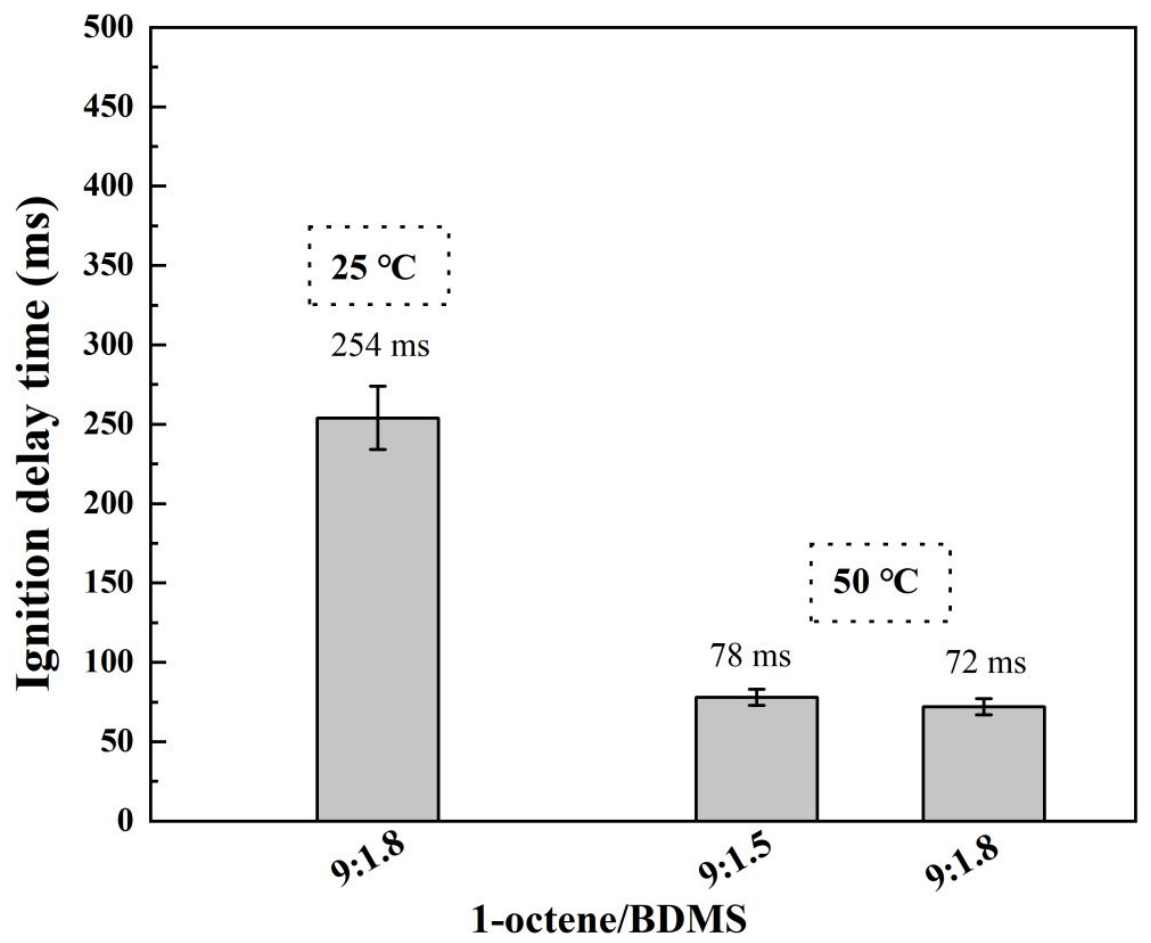

Fig. S1. Ignition delay time of 1-octene/BDMS at various volume ratios.

\section{2. ${ }^{11} B$ NMR (nuclear magnetic resonance) experiment}

${ }^{11} \mathrm{~B}$ NMR spectra were obtained using a Bruker Advance NEO $700 \mathrm{MHz}$ NMR spectrometer equipped with $5 \mathrm{~mm} \mathrm{BBO}$ cryogenic probe at $25^{\circ} \mathrm{C}$. Chemical shifts $(\delta)$ are specified in ppm (parts per million). Pure BDMS and 1-octene/BDMS after reaction dissolved in 1,2-dichlorobenzene- $\mathrm{d}_{4}$ to explore the hydroboration reaction of 1-octene with BDMS and the reaction product via ${ }^{11} \mathrm{~B}$ NMR experiments.

When recording the ${ }^{11} \mathrm{~B}$ NMR spectra of the samples of pure BDMS and 1-octene/BDMS after the reaction, it was found that the characteristic peaks of $\mathrm{BH} 3$ and 1-octene/BDMS changed significantly after the reaction of $\mathrm{BH}_{3}$ with 1-octene. Referring to Fig. S2-a, the characteristic peak at $\delta=20.00 \mathrm{ppm}$ (chemical shift) belongs to $\mathrm{BH}_{3}$. Two broad peaks ( $\delta=87.92$ and $\left.16.01 \mathrm{ppm}\right)$ in Fig. S2-b are attributed to trioctylborane and the oxide of trioctylborane, respectively. ${ }^{1}$ The reasons for the 

product of trioctylborane.

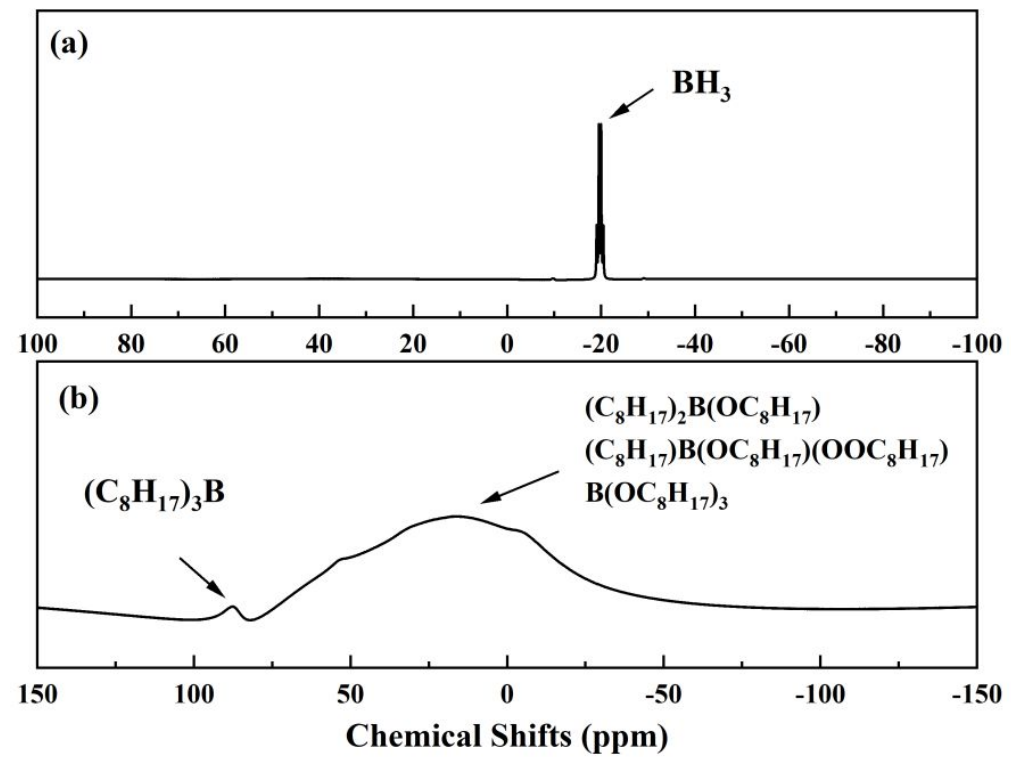

\section{References}

43 (1) Liu, S.J; Zheng, Z.; Li, M.R.; Wang, X.L. Study of the Radical Chemistry

Promoted by Tributylborane. Res. Chem. Intermediat. 2012, 38, 1893-1907. 


\section{Supporting movie legends}

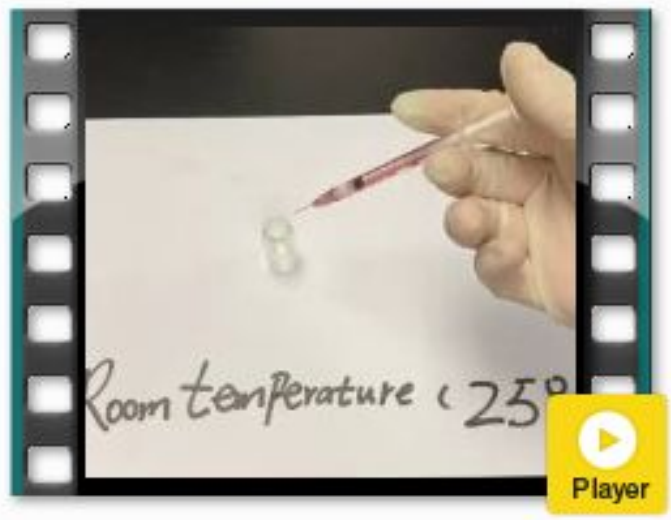

Movie S1 BDMS/1-octene hypergolic ignition at $25^{\circ} \mathrm{C}$.

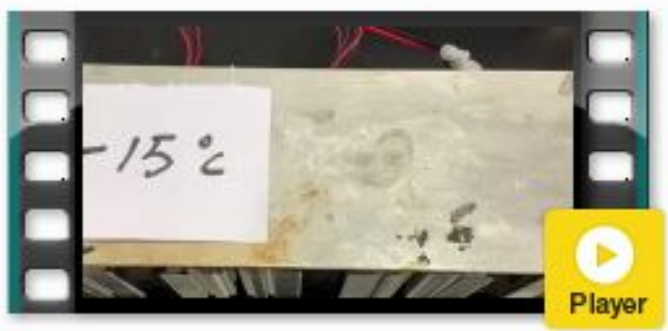

Movie S2 BDMS/1-octene hypergolic ignition at $-15{ }^{\circ} \mathrm{C}$.

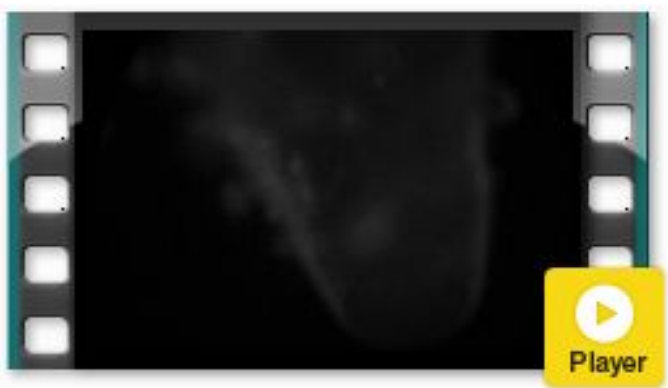

Movie S3 OH radicals in hypergolic ignition process at $-15^{\circ} \mathrm{C}$. 